\title{
Why Pay Attention to You? The Role of Moderation Effects on the Power-Attention Relationship
}

\author{
Emily K. Tarr \\ California State University San Marcos \\ Jeffrey C. Kohles \\ California State University San Marcos
}

Stories in today's society focus poor relationships between leaders or those in high power positions and people lower in power, which may be explained by a pattern found in the literature demonstrating a negative relationship between power and attention to others. We contend that this relationship may have boundary conditions, and this paper proposes and tests such moderators. We propose moderators that will increase the attention of high-power people, and others that will decrease the attention of low-power people. Results from longitudinal data support some moderators for powerholders, the moderators for low-power individuals work in the opposite direction as hypothesized.

\section{INTRODUCTION}

In the wake of the overdue reckoning from the \#MeToo and \#TimesUp movements, where the awareness and impact of power differentials is rippling across business, politics, sports, and entertainment, understanding power dynamics and its outcomes are of paramount importance. While power is the potential to make a difference in the world (Keltner, 2016), too often it is used in the service of the powerholders' self-interests, which may be unethical and even Machiavellian. Otherwise good and decent people can misuse their power, ultimately harming themselves as they may lose influence in the aftermath. On the other side of the equation, individuals who are in positions of low power may be especially concerned with those that have power over them, making them prone to their influence, which can also bring about negative effects for themselves. Being in a low-power position means that one faces greater threats, especially from powerholders. This can easily lead to low-power individuals spending considerable effort trying to manage potential threats in their environment, which can lead to greater experienced chronic stress (Keltner, 2016; Sherman et al., 2012).

One resounding finding in studies on power that may explain these negative outcomes is that highpower people are unlikely to pay attention to those over whom they hold power (Keltner \& Robinson, 1997; Keltner, Gruenfeld, \& Anderson, 2003; Neuberg \& Fiske, 1987), suggesting that they may be unaware of the needs and wants of low-power individuals. In contrast, low-power individuals are likely to devote great attention to those that have power over them. Moreover, due to this increased attention, lowpower people may be spending an undue amount of their finite cognitive resources fixating on those that have power over them rather than concentrating on their work-related tasks and issues. Additionally, 
concentrating greatly on powerholders may deplete their attentional resources, thus decreasing their ability to engage in their work (e.g., Rothbard, 2001; Kahn, 1990), affecting important work outcomes such as job performance and burnout (Rich, LePine, \& Crawford, 2010).

Current theory suggests that attention is driven by people's goals, resulting in great attention paid to objects or people that help one achieve their goals (Dijksterhuis \& Aarts, 2010). Due to their high-power position, powerholders' goals lead them to pay great attention to people or things that can provide them some sort of reward. Since low-power people typically are not in a position to allocate rewards, they garner little of powerholders' attention. However, if there are situations in which high-power people view a low-power counterpart as able to provide them with some sort of reward, this may result in more attention paid to that low-power person. Conversely, low-power individuals are particularly sensitive and motivated to avoid negative outcomes and punishments, which by definition are directly controlled by those that have power over them (Keltner et al., 2003). However, if there are times when low-power people feel assured that powerholders will not allow negative outcomes for them to occur, they may pay less attention to high-power people.

In this paper we propose and test variables as moderators to this power-attention relationship, in search of conditions under which this traditional pattern is reversed. In other words, when may powerholders pay more attention to their low-power counterparts, and when may low-power individuals pay less attention to those that hold power over them? As goals are presumed to underlie the classicallytheorized patterns of attention for low- and high-power individuals, we contend that these moderators will alter the way low- and high-power individuals perceive their counterparts as relevant to their goal attainment, thus changing the way they allocate their attention. Additionally, we use a unique methodology comprised of a longitudinal self-report study, which is a novel way to measure the classic power-attention relationship. In conducting this research, we hope to bring about a better understanding of the prevalent negative outcomes of power dynamics so often witnessed in organizations and in society today, as well as provide insight into how we may change the nature of these dynamics to also realize some of the benefits of power.

\section{THEORETICAL DEVELOPMENT}

Attention is a cognitive and behavioral process marked by orienting toward a person, object, or event (Posner, 1980; Dijksterhuis \& Aarts, 2010; Gardner, Dunham, Cummings, \& Pierce, 1989). Paying attention to others provides valuable information that helps us navigate our environment and facilitate social success (Choleris \& Kavaliers, 1999; Range, Horn, Bugnyar, Gajdon, \& Huber, 2008). In short, we tend to pay attention to the things in our environment that provide us with valuable information (Yarbus, 1967; Mackworth \& Morandi. 1967; Antes, 1974; Buswell, 1935; Henderson \& Hollingworth, 1999; Foulsham, Cheng, Tracy, Henrich, \& Kingstone, 2010). However, attention is a finite resource and we cannot attend to everything in our environment at once, so our attention is selective toward certain aspects of our current environment (Kahneman, 1973; Desimone \& Duncan, 1995). There are two types of influence that determine the direction of our attention: bottom-up and top-down. Bottom-up influences are aspects of the object itself that call our attention to it, such as an object that is flashing, moving, or brightly-colored. Top-down influences, on the other hand, are things about us as the perceivers that affect our attention direction and allocation, such as our prior experiences, values, fears, or our goals (Koch \& Ullman, 1985; Corbetta \& Shulman, 2002; Dehaene, Changeux, Naccache, Sackur, \& Sergent, 2006; Koch \& Tsuchiya, 2006; Land \& Hayhoe, 2001). Considerable research has shown that our goals are an important factor in determining how we direct our attention (see Dijksterhuis \& Aarts, 2010 for a review) and suggests that people pay great attention to people, objects, and events that are in service of goal attainment (e.g., Aarts, Dijksterhuis, \& De Vries, 2001).

Evolutionary theory and, more specifically, the hedonic principle, suggests that we have one main goal: to stay alive. In service of that goal, we have two sub-motivations that may be activated at any time: 1) to approach positive things, or things that will enhance our chances for survival; and 2) to avoid negative things, or things that may harm us or reduce our chances for survival (Buss, 1996; Higgins, 
1997). Theory and research support the notion that the amount of power individuals have affects which of these motivations is more salient (Keltner et al., 2003). High-power people live in a relatively reward-rich world where they feel more free from social consequences and others' judgments (Weber, 1947). This feeling activates the Behavioral Activation System (BAS), which induces individuals to have approachrelated goals (Higgins, 1997, 1998). This BAS creates a context in which all behavior, affect, and cognition is used in service of achieving positive things and things that provide promise of reward (Higgins, 1997; Anderson \& Berdahl, 2002). Since attention is a behavior that is driven by goals, powerholders' attention will be directed toward people and objects with the potential to provide them with rewards. Due to their position, it is unlikely that low-power people are able to provide powerholders with rewards that they could not otherwise attain themselves, and therefore high-power people are unlikely to attend to low-power individuals.

In contrast, low-power people live in a world where they are subjected more to the decisions of those that have power over them, and therefore more consistently feel under threat (Keltner et al., 2003; Fiske, 1993; Steele \& Aronson, 1995). As a result, their Behavioral Inhibition System (BIS) is activated. Akin to an internal alarm system, the BIS induces an avoidance motivation, such that all behavior, affect, and cognition will be used to avoid potential negative results (Higgins, 1997, 1998). By definition, highpower people control the outcomes of those in low power and determine whether they receive the punishments or negative outcomes that low-power people are motivated to avoid. Consequently, lowpower individuals are highly motivated to fix their attention on those that hold power over them, attempting to gain predictability of the intentions and actions of powerholders (Chance, 1967; Ellyson \& Dovidio, 1985; Emory, 1988; Erber \& Fiske, 1984). Although these powerholders may not necessarily behave in ways that are harmful to low-power people (Kipnis, 1972; Chen, Lee-Chai, \& Bargh, 2001), simply paying attention to powerholders may help minimize the uncertainty that low-power individuals face.

Therefore, in replication of prior findings, we propose the following:

Hypothesis 1: There is a negative relationship between power and attention paid to others.

Nascent research (Overbeck \& Park 2001, 2006; De Dreu \& Van Kleef, 2004; Vescio, Snyder, \& Butz, 2003) has begun to uncover boundary conditions (i.e., moderators) to the power-attention relationship, suggesting that there may be situations where the power-attention relationship does not follow the traditionally predicted pattern outlined above. Drawing from these findings, we suggest that since attention is affected by goals (Dijksterhuis \& Aarts, 2010), moderators that affect either the goals that individuals have, or that affect how they see a high- or low-power counterpart in relation to goal achievement, may influence attention. These moderators may either be related to the task or related to the relationship with the relevant other. Extant research in this area (e.g., Overbeck \& Park 2001, 2006; De Dreu \& Van Kleef, 2004; Vescio et al., 2003) tends to focus on task-related moderators, but we suggest that relational moderators could affect attention as well.

Gruenfeld, Inesi, Magee, and Galinsky (2008) found that power increases objectification, a process in which perceivers split up a target into parts and see that target only for the parts which are useful to the perceiver. This may help explain, for example, why high-power individuals may sexually harass lowpower targets. However, this research suggests that powerholders do pay attention to low-power targets at times, but only to the part of the person that they see as useful or gratifying, and not to the "qualities that are valued more generally in social life and that define a person's humanity, such as his or her kindness or morality" (Gruenfeld et al., 2008, p. 111). Therefore, we identify moderators that are more likely to increase attention to the person rather than only pieces of a person that may gratify a powerholders' desires. We propose two relational moderators that may increase the attention of powerholders to their low-power counterparts: similarity, and trust based on ability. While we hypothesize that these variables are likely to increase attention for all individuals regardless of power, we argue that the increase will be especially pronounced for powerholders. In parallel, we also posit two relational moderators that we suggest will decrease the attention of low-power individuals to those that hold power over them: trust 
based on benevolence, and trust based on integrity. Similarly, we hypothesize that these variables will decrease attention for all individuals, but argue that this effect will be especially striking for low-power people.

\section{Moderators that Increase Attention of High-Power Individuals}

All individuals are motivated to see themselves in a positive way, maintaining a positive self-identity (Brockner, 1988; Tajfel \& Turner, 1986), and when we are able to do so, it is rewarding to us. A large part of our self-identity is made up of how we define ourselves in relation to others (i.e., our social identity; Brewer \& Gardner, 1996), and we base much of our self-evaluation on these social identities (Breckler \& Greenwald, 1985; Greenwald \& Breckler, 1985). According to social identification theory (SIT; Tajfel, 1972) and social categorization theory (SCT; Turner, 1982, 1985), we develop our social identity by engaging in a self-categorization process whereby we classify ourselves and others into social categories based on perceived similarities between ourselves and others (Tajfel \& Turner, 1986; Ashforth \& Mael, 1989). Thus, those that we see as similar to ourselves are likely to be included in our in-group. When individuals are members of our in-group, we tend to like them and have positive evaluations of them (Hogg \& Turner, 1985). In contrast, out-group members are perceived as less trustworthy, honest, and cooperative than members of our in-group (Brewer, 1979). More simply, perceiving others as similar to ourselves results in us holding more positive evaluations of them. Interacting and affiliating with others that we hold positive evaluations of can help us achieve a positive self-identity, and this increased interaction and affiliation may require increased attention to them.

Following our inherent self-enhancement motive, SIT and SCT also suggest that we are motivated to achieve positive inter-group distinctiveness (Tajfel \& Turner, 1986; Ashforth \& Mael, 1989). That is, since our in-group is part of who we are and we are motivated to hold a positive self-identity, then we are also motivated to maintain a favorable image of our in-group. Perceived similarity with others means that these people will be included in our in-groups. And, by attending to other in-group members, individuals are also able to gain rewarding benefits and outcomes that result from being associated with that in-group, thus basking in the larger reflected glory.

Hypothesis 2a: There is a positive main effect for similarity on attention, such that perceiving oneself as similar to a target will result in more attention paid to that target.

This effect of similarity on attention may be especially strong for high-power individuals as their activated BAS makes them motivated to achieve things that are rewarding, such as maintaining a positive identity. If low-power individuals are a part of how powerholders socially define themselves, then these powerholders may see them as relevant to goal achievement and therefore pay more attention to them. Thus, high-power individuals, driven by their motive to maintain their positive self-identity, may increase their interaction and affiliation with low-power people they see as similar to themselves, requiring them to pay increased attention to them.

This idea is supported by theory and research on leader-member exchange (LMX), which says that leaders, such as those in high-power positions like supervisors, may have different relationships with each of their subordinates such that some subordinates are considered to be in the leaders' in-groups (Dansereau, Graen, \& Haga, 1975). These relationships with subordinates that are in the in-group are considered high-quality relationships characterized by mutual trust and respect (Gerstner \& Day, 1997). Research on LMX supports the tenets of the similarity-attraction paradigm (Byrne, 1971) by finding that leaders are more likely to have high-quality relationships with subordinates who are perceived as similar to themselves (Yoon \& Bono, 2016; Barbuto \& Gifford, 2012; Liden, Wayne, \& Stilwell, 1993; Cianni \& Romberger, 1995; Turban \& Jones, 1988). Moreover, Dansereau et al. (1975) found that leaders paid much greater attention to subordinates in their in-group. In fact, Yoon and Bono (2016) found that similarity in personality mattered more in the development of LMX for high-power individuals than subordinates, suggesting that this effect is particularly strong for powerholders. 
In sum, when high-power people perceive those in low-power positions to be similar to themselves, they are more likely to see that person as part of their in-group. As members of a powerholders' in-group, these low-power individuals may now be seen as instrumental to achieving the goal of positive selfidentity, which may result in greater attention paid to the low-power person.

Hypothesis 2b: Similarity moderates the relationship between power and attention, such that for highpower individuals, more (less) similarity with a target will result in more (less) attention paid to their low-power counterparts.

In a work environment, individuals may be especially concerned with the ability of those around them to perform. If individuals see coworkers as highly competent and trust their ability to complete work tasks and perform, they may see them as useful in achieving workplace goals. Since theory and research shows that attention serves goal pursuit (Dijksterhuis \& Aarts, 2010), we argue that if individuals have trust in another based on their ability in the workplace, they may be more likely to attend to them.

When a trustor perceives an individual as having high ability in a certain domain, that trustor sees the individual as having the skills and competencies to allow that individual to have relative influence in that domain (Mayer, Davis, \& Schoorman, 1995). By not paying attention to their coworkers, employees may risk missing out on opportunities for others to help them achieve their work-related goals. However, this risk may be mitigated by trusting in a coworker's ability. Since trust becomes relevant in a risky situation when individuals are vulnerable to another (Mayer et al., 1995), employees' trust in their coworkers may affect the employees' attention to them. The increase in attention to others in whom they have high ability-based trust may help them mitigate the risk of missing out on a resource that could help them achieve their goals. If an individual deems a coworker as having high ability, the individual may see that coworker as capable of helping achieve a goal and thus increase his or her attention to the coworker.

Hypothesis 3a: There is a positive main effect for ability-based trust in another on attention, such that having high ability-based trust in a target will result in more attention paid to that target.

This effect of ability-based trust on attention may be especially relevant for high-power individuals as their activated BAS makes them motivated to achieve things that are rewarding. As a result, highpower individuals tend to construe others through a lens of self-interest or, more specifically, they "attend to others in terms of how they enable the power holder to satisfy current goals and desires" (Keltner et al., 2003: 272; Gruenfeld et al., 2008). If high-power individuals perceive high ability in a low-power counterpart, they may see this individual as able to aid in the successful completion of their own work tasks. Therefore, it would be in powerholders' self-interest to focus on those in low power who can help them achieve goals, such as would be the case when powerholders perceive high ability-based trust in a lower-power person.

Hypothesis 3b: Ability-based trust moderates the relationship between power and attention, such that for high-power individuals, having high (low) ability-based trust in a target will result in more (less) attention paid to their low-power counterparts.

\section{Moderators that Decrease Attention of Low-Power Individuals}

When an individual trusts a given target, that individual is willing to be vulnerable to that target based on positive expectations about the target's behavior, independent of an ability to monitor that target. The positive expectations of a trusted other are based on one's perception of the other's trustworthiness, as comprised of three factors: ability (discussed above), benevolence, and integrity (Mayer et al., 1995). Interestingly, the relative importance of these three factors is context-dependent, meaning that there are situations where some factors are more important than others. A trustor perceives an individual to have high benevolence when the trustor thinks the individual has a positive orientation toward the trustor, or a general desire to do good by the trustor. The trustor perceives an individual to have high integrity when 
the trustor believes the individual acts in accordance with a set of values or principles that the trustor deems appropriate (Mayer et al., 1995).

In the absence of trust based on benevolence and integrity, individuals may engage in behaviors to try to manage the uncertainty of the situation. McAllister (1995) proposes that monitoring (i.e., watching or paying close attention to the untrustworthy individual) is one such response to low trust, such that one may monitor the untrustworthy individual in an attempt to gain more certainty that he or she will engage in desired behaviors. Thus, individuals who do not perceive a target to have high benevolence and integrity may be especially attentive to that target.

Hypothesis 4a: There is a negative relationship between benevolence-based trust in a target and attention paid to that target.

Hypothesis 5a: There is a negative relationship between integrity-based trust in a target and attention paid to that target.

The negative relationships hypothesized above may be especially strong for low-power individuals. As previously noted, low-power people will pay attention to those who have power over them because of their vulnerability to powerholders (Keltner et al., 2003). Part of their vulnerability relates to dependence on others for their outcomes, resulting in a prevention focus, meaning low-power individuals are highly motivated to avoid negative outcomes (Keltner et al., 2003). However, trusting a person who has power over oneself may increase one's willingness to accept that vulnerability of being at the mercy of the powerful (Mayer \& Gavin, 2005). This, in turn, may render less relevant the need to pay attention to the powerful in an attempt to predict their behaviors and intentions.

Low-power individuals are especially concerned with how powerholders control their outcomes, resources, and punishments, which suggests that a powerholder's benevolence and integrity may be especially important in the decisions low-power individuals make about trusting those with power. If a low-power actor holds high trust in a powerful individual that is based on perceptions of high integrity and benevolence, they will likely have positive expectations that the powerful person will control their resources in a positive and fair way. In this case, low-power actors are less likely to see the powerful person as a threat and therefore may pay less attention to them.

Hypothesis 4b: Benevolence-based trust moderates the relationship between power and attention, such that for low-power individuals, having high (low) benevolence-based trust in a target will result in less (more) attention paid to their high-power counterparts.

Hypothesis 5b: Integrity-based trust moderates the relationship between power and attention, such that for low-power individuals, having high (low) integrity-based trust in a target will result in less (more) attention paid to their high-power counterparts.

\section{METHODS}

Data were collected from respondents using Qualtrics Panels at two time periods, one month apart (Time 1, $N=511$; and Time 2, $N=223$ ). The use of Qualtrics Panels ensured that repondents varied widely in job positions, and types of organizations, as well as personal and demographic characteristics, thus lending the results greater external validity (see Brandon, Long, Loraas, Mueller-Phillips, \& Vansant, 2014). Moreover, Qualtrics utilizes by-invitation-only online panel recruitment, thus avoiding selfselection and professional survey takers. Participants were instructed to choose a target co-worker with whom they have contact at least on a daily basis (on average), and respond to a variety of measures with that target in mind. Half of the participants were instructed to choose a target who has power over them, while the other half were instructed to choose a target over whom $\mathrm{s} /$ he holds power. The purpose of this 
was to ensure that we achieved variance on the power measure, rather than respondents simply choosing targets at similar levels of power to themselves.

At Time 1, respondents indicated their level of power relative to the target, as well as control variables. At Time 2, participants completed measures of the moderators as well as their attention paid to the target. Measuring the moderators at Time 2 allows for a test of how concurrent perceptions of the relational variables (used as moderators) affect attention at that time. As discussed above, theory suggests that attention is affected by current (i.e., immediately-relevant) goals (Dijksterhuis \& Aarts, 2010), and we argue that the proposed moderators affect a focal person's current goals and thus his or her attention. Thus, since current or relevant goals may change between measurement times, using measurements of the moderators at the same time as attention is a better test of whether the moderators affect attention. Morevoer, the use of two time points that span over a month allows for a meaningful amount of time between the measure of the independent (power) and dependent (attention) variables.

\section{Measures}

Attention

At Time 1, attention to a target was measured using a modified version from Rothbard's (2001) selfreported 3-item engagement scale measuring attention: "I focus a great deal of attention on this person," "I concentrate a lot on this person," and "I pay a lot of attention to this person" $(\alpha=0.85 ; 1=$ strongly disagree, 5 = strongly agree).

\section{Power}

Respondents were instructed to pick a target that either they had power over or that had power over them, resulting in variance that allowed us to use a continuous measure of power in the analyses $(\mathrm{M}=$ 3.03; SD = 1.03). Hinkin and Schriesheim's (1989) measures of coercive and reward power were used and combined for an overall 8 -item power measure $(\alpha=0.88 ; 1=$ strongly disagree, $5=$ strongly agree $)$. These two scales were chosen rather than the other measures (legitimate, referent, and expert) because they fit the definition of power used in this paper: "one's relative control over valued resources and the capacity to administer rewards and punishments" (Keltner et al., 2003; Emerson, 1962). Since this definition encompasses both administering rewards (reward power) and administering punishments (coercive power), there is a theoretical basis to justify the combination of these two scales to measure power. The scale was prompted with "I believe this person can..." and sample items include: "Increase my pay level," and "Make work difficult for me."

\section{Similarity}

Similarity was measured using a 4-item scale from Back and Lips (1998). Sample items include, "I feel that I am similar to this person" and "This person reminds me of myself" $(\alpha=0.95 ; 1=$ strongly disagree, $5=$ strongly agree).

\section{Trust}

Trust based on benevolence, integrity, and ability were measured using Mayer and Davis's (1999) scales. The measure for benevolence-based trust consists of five items ( $\alpha=0.92 ; 1=$ strongly disagree, 5 = strongly agree), including, "This person is very concerned about my welfare." The measure of integritybased trust consists of six items $(\alpha=0.88)$, including "This person has a strong sense of justice." The last measure of trust, ability-based trust, consists of six items $(\alpha=0.95)$ including, "This person is very capable of performing his/her job."

\section{Control Variables}

Since theory on trust suggests that it develops over time and through recurring interactions (Lewicki \& Bunker, 1995), length of relationship with one's chosen target was controlled for with one item, "How long have you known this individual?", and frequency of interaction was controlled for with one item, 
"On average, how frequently do you have interactions with this person?" Response choices included: $1=$ Once a week, 2 = Several times a week, $3=$ Once a day, $4=2-3$ times a day, $5=4-5$ times $a$ day or more). Tenure and gender, as well as the gender of the target, were also controlled for as these may affect attention (e.g., Koch \& Ullman, 1985), or perceptions of power (French \& Raven, 1959; Henley \& LaFrance, 1984).

Whether one has a formal direct-report power relationship with their counterpart was also controlled for by asking, "Do you/does this person hold a formal position of authority over this person/you (for example, supervisor or boss)?" This variable was dummy-coded $(1=$ yes, $2=$ no $)$ in analyses.

\section{RESULTS}

Means, standard deviations, and intercorrelations for the variables in this study can be found in Table 1, and regression results from Hypotheses 1-5 can be found in Table 2. In support of Hypothesis 1, a regression analysis showed a significant negative relationship between power at Time 1 and attention at Time $2(\beta=-0.15, p=.02)$.

Hypotheses $2 \mathrm{a}$ through $3 \mathrm{~b}$ make predictions about moderators that will increase attention for highpower individuals. Hypothesis $2 \mathrm{a}$ was supported, finding a significant main effect of perceived similarity with the target on attention paid to that target $(\beta=0.32, p<0.01)$. Hypothesis $2 \mathrm{~b}$ predicted that an individual's perception of a counterpart's similarity to oneself would moderate the relationship between power and attention such that attention would increase with greater levels of similarity for high-powered individuals. A regression analysis revealed a significant interaction $(\beta=-0.10, p=0.04)$. In order to interpret the form of the interaction, we used the method suggested by Preacher, Curran, and Bauer (2006) and plotted the relationship between power and similarity ratings at one standard deviation above and below the mean. By looking at the figure (Figure 1), we can see that high-power individuals' attention does increase when they perceive high similarity with the low-power counterpart, thus supporting Hypothesis $2 \mathrm{~b}$. However, similarity also increases the attention of low-power individuals, which is an unexpected finding.

Hypothesis 3a was supported as well, finding a positive and significant main effect of ability-based trust on attention $(\beta=0.34, p<0.01)$. Hypothesis $3 \mathrm{~b}$ predicted that power and trust based on ability would interact such that attention would increase for high-powered individuals with high trust based on ability. However, there was no significant interaction and this hypothesis was not supported $(\beta=-0.003, p$ $=0.96$ ).

In support of Hypothesis $4 \mathrm{a}$, a regression analysis showed a significant main effect of benvolencebased trust on attention $(\beta=0.46, p<0.01)$, but in a positive direction, contrary to our prediction. Similarly, Hypothesis 5a was also not supported, with a significant but positive main effect of integritybased trust on attention $(\beta=0.33, p<0.01)$. Finally, Hypotheses $4 \mathrm{~b}$ and $5 \mathrm{~b}$ made predictions about moderators that would decrease the attention of low-power individuals. Specifically, these hypotheses predicted that an individual's perception of his or her counterpart's benevolence and integrity would moderate the relationship between power and attention such that attention would decrease with greater levels of benvolence-based trust (Hypothesis $4 \mathrm{~b}$ ) and integrity-based trust (Hypothesis $5 \mathrm{~b}$ ) for lowpowered individuals. Regression analyses revealed no significant interaction for Hypothesis $4 \mathrm{~b}$ ( $\beta=-$ $0.006, p=0.92)$. However, for Hypothesis $5 \mathrm{~b}$, the test of the moderation for integrity-based trust on the power-attention relationship was significant $(\beta=-0.12, p=0.05)$. Following the methods suggested by Preacher and colleagues (2006), we plotted the interaction (see Figure 2). However, we found that, again, the interaction does not follow the predicted direction of Hypothesis 5b. More specifically, instead of greater levels of integrity-based trust decreasing low-power individuals' attention, it increases their attention. Additionally, we can also see an increase in high-power individuals' attention with greater levels of integrity-based trust. Therefore, Hypothesis $5 \mathrm{~b}$ is not supported.

Journal of Organizational Psychology Vol. 19(2) 2019151 


\section{DISCUSSION}

The main purpose of this study was to test the role of moderators on the relationship between power and attention. Our results suggest times or conditions in which the normal attentional patterns of low- and high-power individuals may not hold. More specifically, we made predictions about times in which powerholders' attention to low-power people would increase, and low-power inidividuals' attention to those that have power over them would decrease. We found support for one of our moderation hypotheses regarding high-power people, in that when they perceive themselves as similar to a low-power individual, they are likely to increase their attention to them. Interestingly, perceived similarity also increased lowpower people's attention. We did not find support in the predicted direction for our hypotheses about moderators that would decrease low-power individuals' attention.

However, an interesting pattern emerged in our results. In general, for both high- and low-power individuals, when people perceive positive characteristics about targets, their attention to that target increases. Specifically, we found consistent, positive main effects for all of the moderator variables we tested. While some of the interactive effects were not significant, this result came through as a main effect for each of the three types of trust: ability-, benevolence-, and integrity-based trust (see Table 2). This finding is particularly interesting given the notion that high levels of trust may decrease the amount of attention one pays to others (e.g., McAllister, 1995; Mayer \& Gavin, 2005). In the case of high-power individuals, their trust was affected especially by ability-based trust, following our reasoning that when they percieve a low-power person as having high ability, that person may be seen as instrumental to powerholders' goal attainment. However, the effect of trust on low-power individuals' attention is puzzling. While we predicted that trust based on benevolence and integrity would have a dampening effect on their attention, we found that it instead had an additive effect, such that having high integritybased trust in a high-power person actually increased the already high levels of attention paid to powerholders. The results for high-power individuals support Overbeck and Park's (2006) assertion that powerholders use their attention flexibly, meaning they are able to use attention as a resource to achieve their current goals. Conversely, the results for low-power individuals may suggest that these individuals do not hold this same capacity for flexible attention. Instead, even if they hold high trust in powerholders based on perceptions of their integrity, this may not temper their primary goal of avoiding negative outcomes. Alternatively, it may be the case that low-power individuals pay more attention to high-power people with integrity because they perceive leadership or mentorship qualities that they are attracted to.

Extant research has identified task-specific goals as moderators to the power-attention relationship (Overbeck \& Park 2001, 2006; De Dreu \& Van Kleef, 2004; Vescio et al., 2003), but the findings from our study support additional moderating variables that are more relational in nature. This suggests that certain features of the relationship that high-power individuals have with people over whom they hold power may shape their behaviors toward those individuals, such as attention, by affecting whether they see these individuals as having the potential to provide them with rewards. Prior research has found that power increases the likelihood of objectifying people such that they approach useful targets "regardless of the value of their other human qualities" (Gruenfeld et al., 2008, p. 111), painting a negative picture of powerholders' approach to others. However, the finding from our study that similarity with a low-power target increases attention toward that target suggests that powerholders are not simply blind to these "human qualities." Instead, maintaining a positive relationship with that person may be seen as rewarding to powerholders. In this case, they would no longer be objectifying the low-power target, and instead would be concerned with that individual's needs, interests, and experiences. Therefore, these results are promising especially in regards to high-power individuals. Research tends to repeatedly find that power has negative effects on powerholders (see Keltner, et al. 2003 and Keltner, 2016 for a review) like paying less attention to low-power others. It is clear that powerholders' attention is driven by self-gratification, but our research reveals times in which this self-gratification is not at the expense of low-power people. 


\section{Limitations and Future Research}

A potential limitation to this research is that the data are all self-report. However, this concern may be mitigated by our use of longitudinal methodology. More specifically, since the independent and dependent variabels were collected at different times, this may reduce the chances of common method bias. Furthermore, self-report data are particularly appropriate in this study for several reasons. First, it is the perceived psychological experience of power that should theoretically affect individuals' attention toward others. Therefore, it is important to measure self-perceptions of power. Second, the moderators are also relational variables, which require self-reported perceptions. Attention is appropriate to measure with self-report as well. While we may not always be aware of the direction of our attention, it would be very difficult to employ other measures to gauge attention to others in the workplace. One potential option for this is the use of eye-tracking devices (such as Tobii) that can be worn like glasses. Since gaze is a reliable indicator of attentional direction (Henderson, 2003), this may be another way to capture an objective measure of attention. However, not only does this method seem highly impractical, but the awareness of wearing an eye-tracking device may affect individuals' attention in ways such that true attentional patterns are not captured. Yet, this does suggest an avenue for future research to investigate whether self-reported attention correlates with an objective measure of attention.

Another area of potential research includes investigating moderating variables for the power-attention relationship that are perceived to be more negative in nature. While the moderating variables in the current study are positive (e.g., types of trust), further research could look at conditions where high- or low-power individuals perceive unflattering or even toxic qualities in their counterparts. Would they pay less attention to these people and merely write them off, or pay more attention to them because they could represent some sort of threat or danger? Finally, does distance, either geographical or virtual (i.e., meditated through technology), impact the effect that power has on the attention we pay to others?

\section{Practical Implications}

Unfortunately, in both organizations and society at large, it is all too easy to understand why powerholders are likely to abuse their power by only paying attention to low-power individuals when they see them as more easily manipulated. Fortunately the \#MeToo and \#TimesUp movements have begun to shed more light on these unethical practices. Furthermore, this current research begins to uncover how we can encourage powerholders to attend to low-power individuals by perceiving them more relationally, and through more positive qualities like similarity and various forms of trust that they see in those low-power individuals.

Specifically, more progressive organizational practices that promote empowerment, as well as diverse teams including a mix of higher and lower power individuals, should naturally encourage high-power people to see those qualities in their low-power counterparts and, therefore, attend to them more. By giving more attention to low-power individuals, powerholders are then able to give opportunities to positively influence those people. Another byproduct, of course, could be improved leadership and mentorship processes that further develop and advance those with lower power.

A final note of practical significance from this research concerns whom both high- and low-power individuals are paying attention to, namely those we relate to and trust. Of particular interest here is integrity-based trust, and our encouraging results that both low-power and high-power people pay attention to their counterparts whom they see as having integrity and character. In the post-truth era, with powerful and sometimes toxic leaders among us, it is reassuring that under the right conditions even the powerful can take positive notice of those without power and, for the most part, we are all still looking toward those who embody integrity that we can trust. 


\section{REFERENCES}

Aarts, H., Dijksterhuis, A., \& De Vries, P. (2001). On the psychology of drinking: Being thirsty and perceptually ready. British Journal of Psychology, 92, 631-642.

Anderson, C., \& Berdahl, J.L. (2002). The experience of power: Examining the effects of power on approach and inhibition tendencies. Journal of Personality and Social Psychology, 83, 13621377.

Antes, J.R. (1974). The time course of picture viewing. Journal of Experimental Psychology, 103(1), 6270.

Ashforth, B.E., \& Mael, F. (1989). Social identity theory and the organization. Academy of Management Review, 14, 20-39.

Back, S., \& Lips, H.M. (1998). Child sexual abuse: Victim age, victim gender and observer gender as factors contributing to attributions of responsibility. Child Abuse \& Neglect, 22(12), 1239-1252.

Barbuto, J.E., \& Gifford, G.T. (2012). Motivation and leader-member exchange: Evidence counter to similarity attraction theory. International Journal of Leadership Studies, 7, 18-28.

Brandon, D.M., Long, J.H., Loraas, T.M., Mueller-Phillips, J., \& Vansant, B. (2014). Online instrument devliery and participant recruitment services: Emerging opportunities for behavioral accounting research. Behavioral Research in Accounting, 26(1), 1-23.

Breckler, S.J., \& Greenwald, A.G. (1986). Motivational facets of the self. In E.T. Higgins \& R. Sorrentino (Eds.), Handbook of motivation and cognition (Vol. 1, pp. 145-164). New York: Guilford Press.

Brewer, M.B. (1979). In-group bias in the minimal intergroup situation: A cognitive motivational analysis. Psychological Bulletin, 86, 307-324.

Brewer, M.B., \& Gardner, W. (1996). Who is this "we"? Levels of collective identity and self representation. Journal of Personality and Social Psychology, 71(1), 83-93.

Brockner, J. (1988). Self Esteem at Work: Research, Theory, and Practice. Lexington, MA: Heath.

Buss, D.M. (1996). The evolutionary psychology of human social strategies. In E.T. Higgins \& A.W. Kruglanski (Eds.), Social psychology: Handbook of basic principles (pp. 3-38). New York, NY: Guilford Press.

Buswell, G.T. (1935). How people look at pictures: A study of the psychology and perception in art. Oxford: University of Chicago Press.

Chance, M.R.A. (1967). Attention structure as the basis of primate rank order. Man, 2, 503-518.

Chen, S., Lee-Chai, A.Y., \& Bargh, J.A. (2001). Relationship orientation as a moderator of the effects of social power. Journal of Personality and Social Psychology, 80(2), 173-187.

Choleris, E., \& Kavaliers, M. (1999). Social learning in animals: Sex differences and neurobiological analysis. Pharmacology Biochemistry and Behavior, 64(4), 767-776.

Cianni, M., \& Romberger, M. (1995). Percieved racial, ethnic, and gender differences in access to developmental experiences. Group and Organization Management, 20(4), 440-459.

Corbetta, M. \& Shulman, G.L. (2002). Control of goal-directed and stimulus-driven attention in the brain. Nature Reviews Neuroscience, 3(3), 201-215.

Dansereau, F., Graen, G., \& Haga, W.J. (1975). A vertical dyad linkage approach to leadership within formal organizations: A longitudinal investigation of the role making process. Organizational Behavior and Human Performance, 13, 46-78.

De Dreu, C.K.W., \& Van Kleef, G.A. (2004). The influence of power on the information search, impression formation, and demands in negotiation. Journal of Experimental Social Psychology, 40(3), 303-319.

Dehaene, S., Changeux, J.P., Naccache, L., \& Sackur, J., \& Sergent, C. (2006). Conscious, preconscious, and subliminal processing: A testable taxonomy. Trends in Cognitive Sciences, 10(5), 204-211.

Desimone, R. \& Duncan, J. (1995). Neural mechanisms of selective visual attention. Annual Review of Neuroscience, 18(1), 193-222. 
Dijksterhuis, A., \& Aarts, H. (2010). Goals, attention, and (un)consciousness. Annual Review of Psychology, 61, 467-490.

Ellyson, \& Dovidio (1985). Power, dominance, and nonverbal behavior: Basic concepts and issues. In S.L. Ellyson \& J.F. Dovidio (Eds.), Power, Dominance, and Nonverbal Behavior (pp. 1-27). New York, NY: Springer.

Emerson, R.M. (1962). Power-dependence relations. American Sociological Review, 27(1), 31-41.

Emory, R. (1988) Social geometry and cohesion in three primate species. In M.R.A. Chance (Ed.), Social fabrics of the mind (pp. 47-60). East Sussex, England: Erlbaum.

Erber, R., \& Fiske, S.T. (1984). Outcome dependency and attention to inconsistent information. Journal of personality and social psychology, 47(4), 709-726.

Fiske, S.T. (1993). Controlling other people: The impact of power on stereotyping. American Psychologist, 48, 621-628.

Foulsham, T., Cheng, J.T., Tracy, J.L, Henrich, J, \& Kingstone, A. (2010). Gaze allocation in a dynamic situation: Effects of social status and speaking. Cognition, 117, 319-331.

French, J.R., \& Raven, B. (1959) The bases of social power. In D. Cartwright (ed.), Studies in Social Power (pp. 150-167). Ann Arbor, MI: Institute for Social Research.

Gardner, D.G., Dunham, R.B., Cummings, L.L., \& Pierce, J.L. (1989). Focus of attention at work: Construct definition and empirical validation. Journal of Occupational Psychology, 62, 61-77.

Gerstner, C.R., \& Day, D.V. (1997). Meta-analytic review of leader-member exchange theory: Correlates and construct issues. Journal of Applied Psychology, 82(6), 827-844.

Greenwald, A.G., \& Breckler, S.J. (1985). To whom is the self presented? In B. Schlenker (Ed.), The self and social life (pp. 126-145). New York: McGraw-Hill.

Gruenfeld, D.H., Inesi, M.E., Magee, J.C., \& Galinsky, A.D. (2008). Power and the objectification of social targets. Journal of Personality and Social Psychology, 95, 111-127.

Henderson, J.M. (2003). Human gaze control during real-world scene perception. Trends in Cognitive Sciences, 7(11), 498-504.

Henderson, J.H. \& Hollingworth, A. (1999). The role of fixation position in detecting scene changes across saccades. Psychological Science, 10(5), 438-443.

Henley, N.M., \& LaFrance, M. (1984). Gender as culture: Difference and dominance in nonverbal behavior. In A. Wolfgang (Ed.) Nonverbal behavior: Perspectives, applications, intercultural insights (pp. 351-371). Ashland, OH: Hogrefe \& Huber Publishers.

Higgins, E.T., (1997). Beyond pleasure and pain. American Psychologist, 52(12), 1280-1300.

Higgins, E.T. (1998). Promotion and prevention as motivational duality: Implications for evaluative processes. In S. Chaiken \& Y. Trope (Eds.), Dual-process theories in social psychology (pp. 503525). New York: Guilford Press.

Hinkin, T.R., \& Schreisheim, C.A. (1989). Development and application of new scales to measure the French and Raven (1959) bases of social power. Journal of Applied Psychology, 74(4), 561-567.

Hogg, M. \& Turner, J.C. (1985). Interpersonal attraction, social identification and psychological group formation. European Journal of Social Psychology, 15, 51-66.

Kahn, W.A. (1990). Psychological conditions of personal engagement and disengagement at work. Academy of Management Journal, 33, 692-724.

Kahneman, D. (1973). Attention and effort. Englewood Cliffs, NJ: Prentice-Hall.

Keltner, D. (2016). The power paradox: How we gain and lose influence. New York: Penguin Books.

Keltner, D., Gruenfeld, D.H., \& Anderson, C. (2003). Power, approach, and inhibition. Psychological Review, 110(2), 265-284.

Keltner, D., \& Robinson, R.J. (1997). Defending the status quo: Power and bias in social conflict. Personality and Social Psychology Bulletin, 23(10), 1066-1077.

Kipnis, D. (1972). Does power corrupt? Journal of Personality and Social Psychology, 24, 33-41.

Koch, C., \& Tsuchiya, N. (2006). Attention and consciousness: Two distinct brain processes. Trends in Cognitive Science, 11, 16-22. 
Koch, C., \& Ullman, S. (1985). Shifts in selective visual attention: Towards the underlying neural circuitry. Human Neurobiology, 4(4), 219-227.

Land, M.F., \& Hayhoe, M. (2001). In what ways do eye movements contribute to everyday activies?. Vision Research, 41(25), 3559-3565.

Lewicki, R. J., \& Bunker, B. B. (1995). Trust in relationships. Administrative Science Quarterly, 5(1), 583-601.

Liden, R.C., Wayne, S.J., \& Stilwell, D. (1993). A longitudinal study on the early development of leadermember exchanges. Journal of Applied Psychology, 78(4), 662-674.

Mackworth, N.H., \& Morandi, A.J. (1967). The gaze selects informative details within pictures. Perception \& Psychophysics, 2(11), 547-552.

Mayer, R.C. \& Davis, J.H. (1999). The effect of the performance appraisal system on trust for management: A field quasi-experiment. Journal of Applied Psychology, 84, 123-136.

Mayer, R.C., Davis, J.H., \& Schoorman, F.D. (1995). An integrative model of organizational trust. Academy of Management Review, 20(3), 709-734.

Mayer, R.C., \& Gavin, M.B. (2005). Trust in management and performance: Who minds the shop while the employees watch the boss? Academy of Management Journal, 48(5), 874-888.

McAllister, D.J. (1995). Affect- and cognition-based trust as foundations for interpersonal cooperation in organizations. Academy of Management Journal, 38(1), 24-59.

Neuberg, S.L., \& Fiske, S.T. (1987). Motivational influences on impression formation: Outcome dependency, accuracy-driven attention, and individuating processes. Journal of Personality and Social Psychology, 53(3), 431-444.

Overbeck, J.R., \& Park, B. (2001). When power does not corrupt: Supervior individuation processes among powerful perceivers. Journal of Personality and Social Psychology, 81(4), 549-565.

Overbeck, J.R., \& Park, B. (2006). Powerful perceivers, powerless objects: Flexibility of powerholders' social attention. Organizational Behavior and Human Decision Processes, 99, 227-243.

Posner, M.I. (1980). Orienting of attention. Quarterly Journal of Experimental Psychology, 32(1), 3-25.

Preacher, K.J., Curran, P.J., \& Bauer, D.J. (2006). Computational tools for probing interactions in multiple linear regression, multilevel modeling, and latent curve analysis. Journal of Educational and Behavioral Statistics, 31(4), 437-448.

Range, F., Horn, L., Bugnyar, T., Gajdon, G.K., Huber, L. (2009). Social attention in keas, dogs and human children. Animal Cognition, 12(1), 181-192.

Rich, B.L., LePine, J.A., \& Crawford, E.R. (2010). Job engagement: Antecedents and effects on job performance. Academy of Management Journal, 53(3), 617-635.

Rothbard, N.P. (2001). Enriching or depleting? The dynamics of engagement in work and family roles. Administrative Science Quarterly, 46(4), 655-684.

Sherman, G. D., Lee, J. J., Cuddy, A. J., Renshon, J., Oveis, C., Gross, J. J., \& Lerner, J. S. (2012). Leadership is associated with lower levels of stress. Proceedings of the National Academy of Sciences, 109(44), 17903-17907.

Steele, C.M., \& Aronson, J. (1995). Stereotype threat and the intellectual test performance of African Americans. Journal of Personality and Social Psychology, 69(5), 797-811.

Tajfel, H. (1972). Social categorization. English manuscript of "La categorisation social." In S. Moscovici (Ed.), Introduction a psychologie sociale (Vol. 1) Paris: Larousse.

Tajfel, H. \& Turner, J.C. (1986). The social identity theory of intergroup behavior. In S. Worchel \& W.G. Austin (Eds.), Psychology of Intergroup Relations (pp. 7-24). Chicago: Nelson-Hall.

Turban \& Jones, (1988). Supervisor-subordinate similarity: Types, effects, and mechanisms. Journal of Applied Psychology, 73(2), 228-234.

Turner, J.C. (1982). Toward a cognitive redefinition of the social group. In H. Tajfel (Ed.), Social identity and intergroup relations (pp. 15-40). Cambridge: Cambridge University Press.

Turner, J.C. (1985). Social categorization and the self-concept: A social-cognitive theory of group behavior. In E.J. Lawler (Ed.), Advances in group processes: Theory and reserach (Vol. 2, pp. 77-121). Greenwich, CT: JAI Press. 
Vescio, T.K., Snyder, M., \& Butz, D. (2003). Power in stereotypically masculine domains: A social influence strategy x stereotype match model. Journal of Personality and Social Psychology, 85, 1062-1078.

Weber, M. (1947). The theory of social and economic organization. (A.M. Henderson \& T. Parsons, Trans.). New York: Oxford University Press.

Yarbus, A.L. (1967). Eye movements and vision. New York: Plenum.

Yoon, D.J. \& Bono, J.E. (2016). Hierarchical power and personality in leader-member exchange. Journal of Managerial Psychology, 31(7), 1198-1213. 


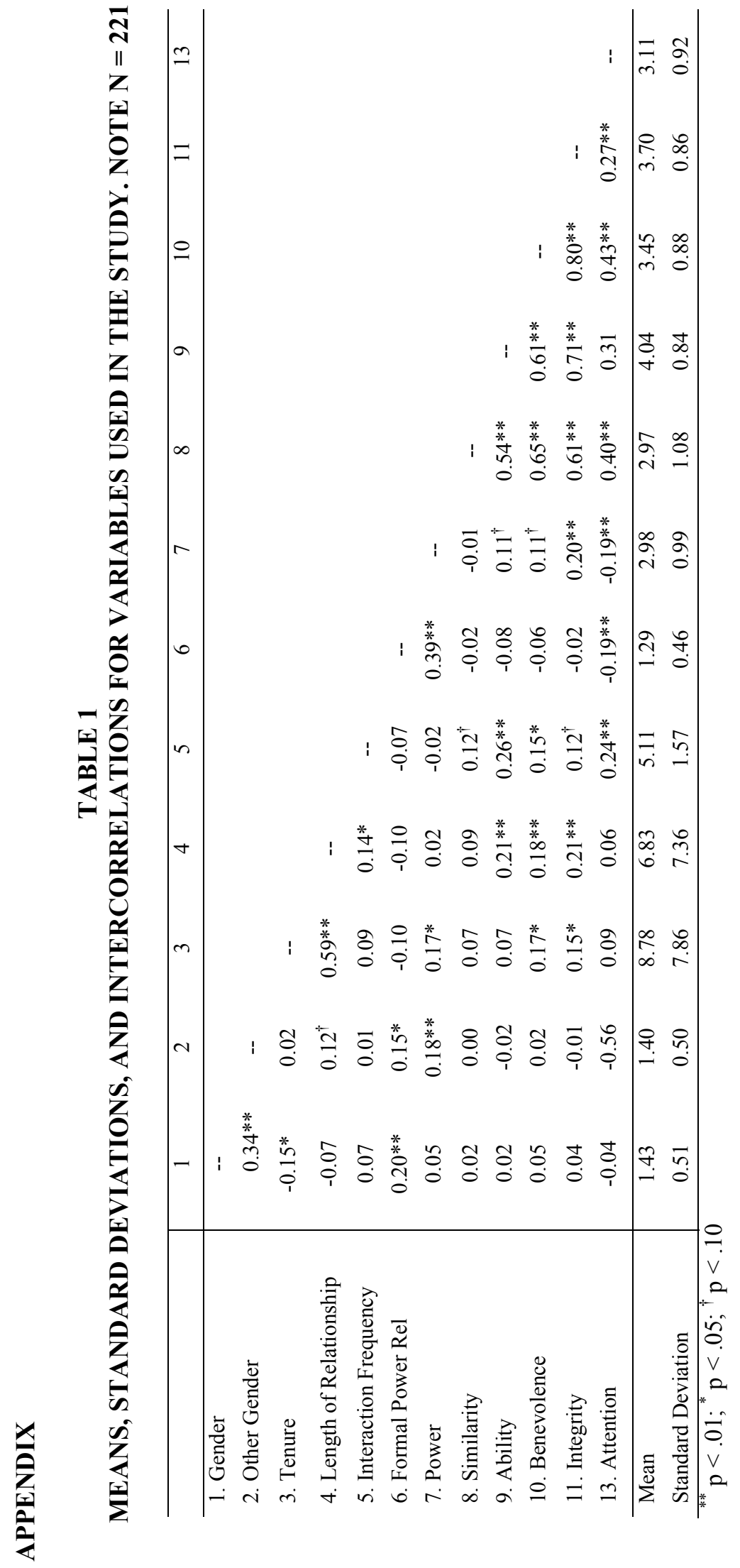




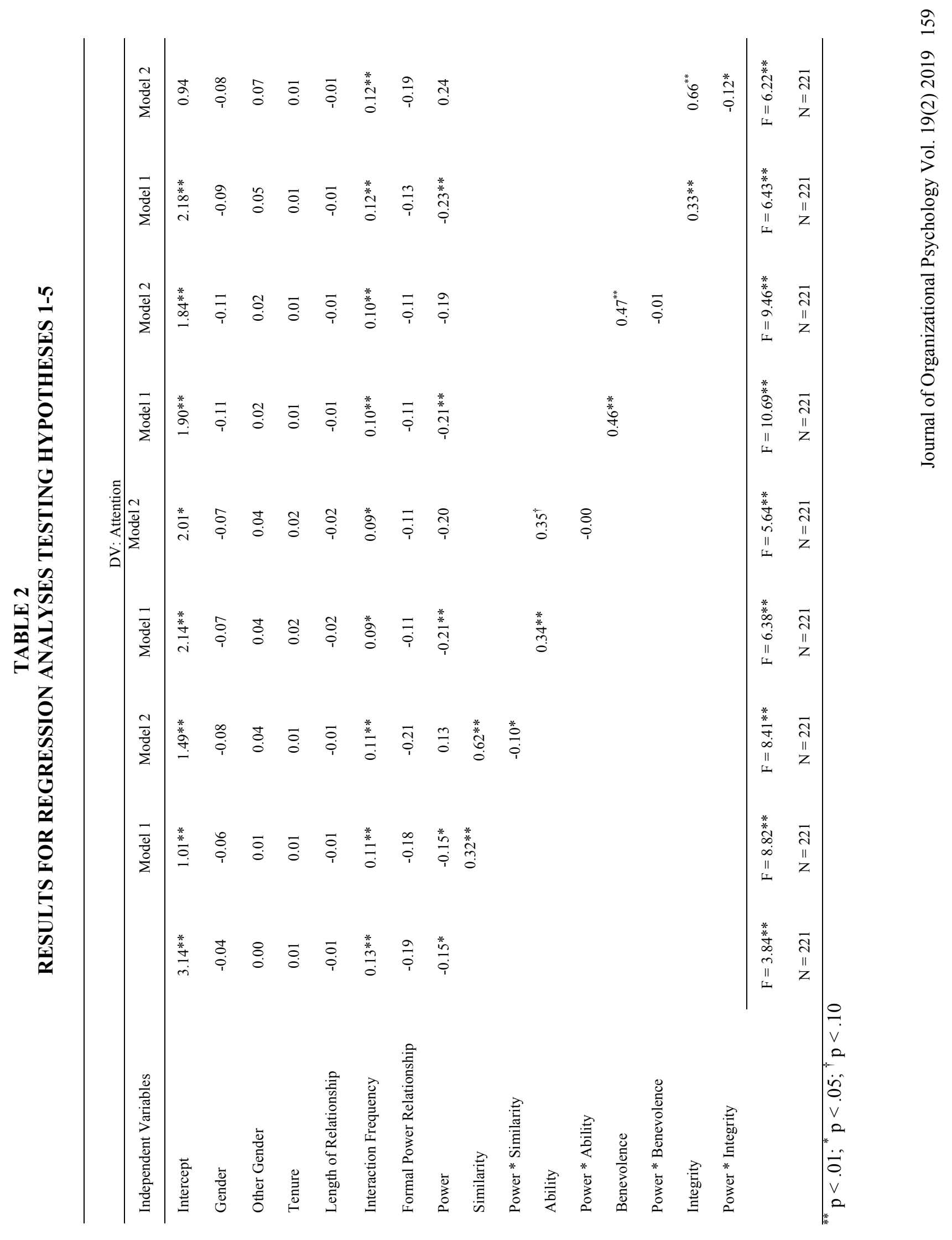


FIGURE 1

THE INTERACTIVE EFFECT OF POWER AND SMILIARITY ON ATTENTION

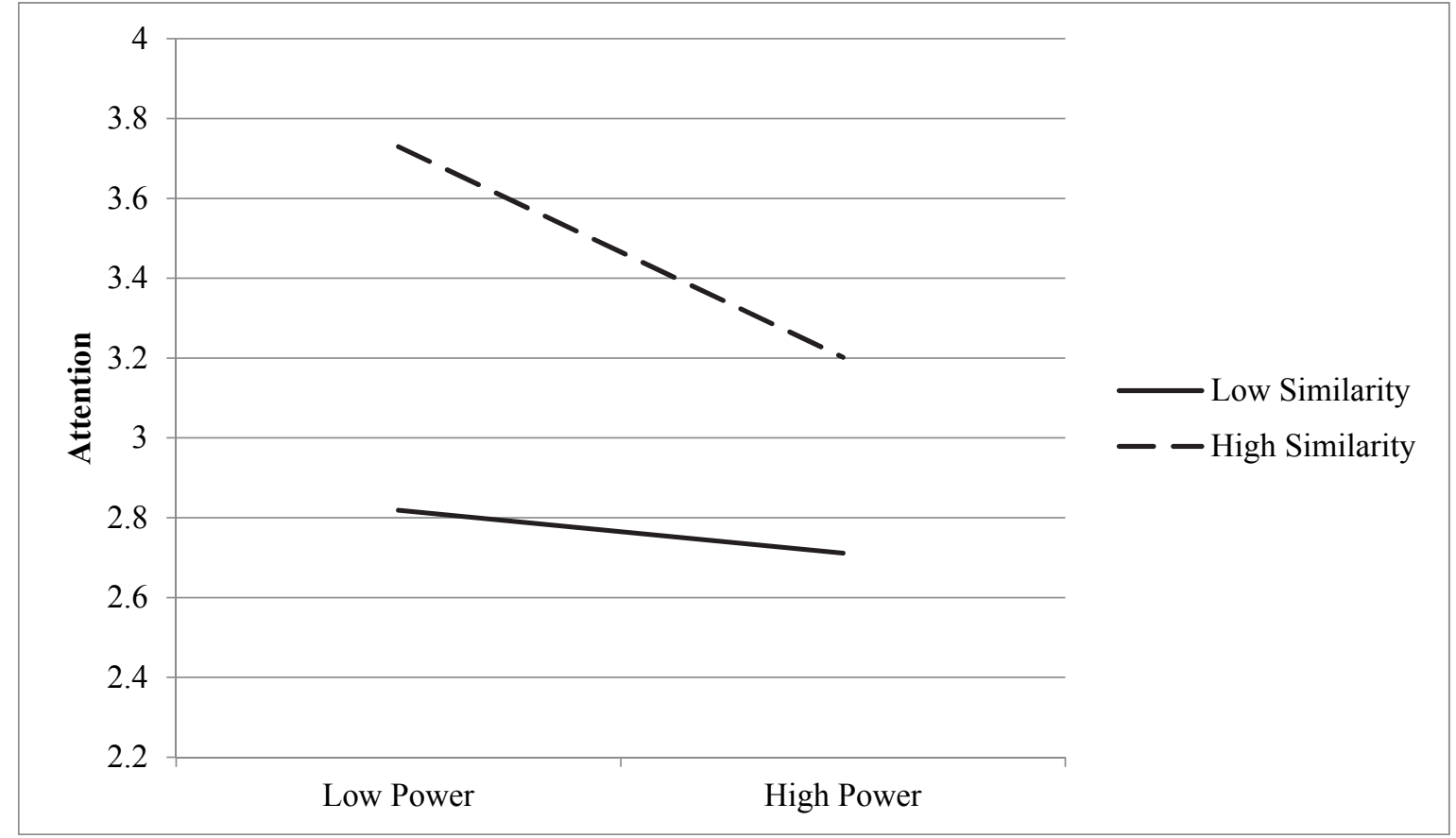

FIGURE 2

THE INTERACTIVE EFFECT OF POWER AND INTEGRITY-BASED TRUST ON ATTENTION

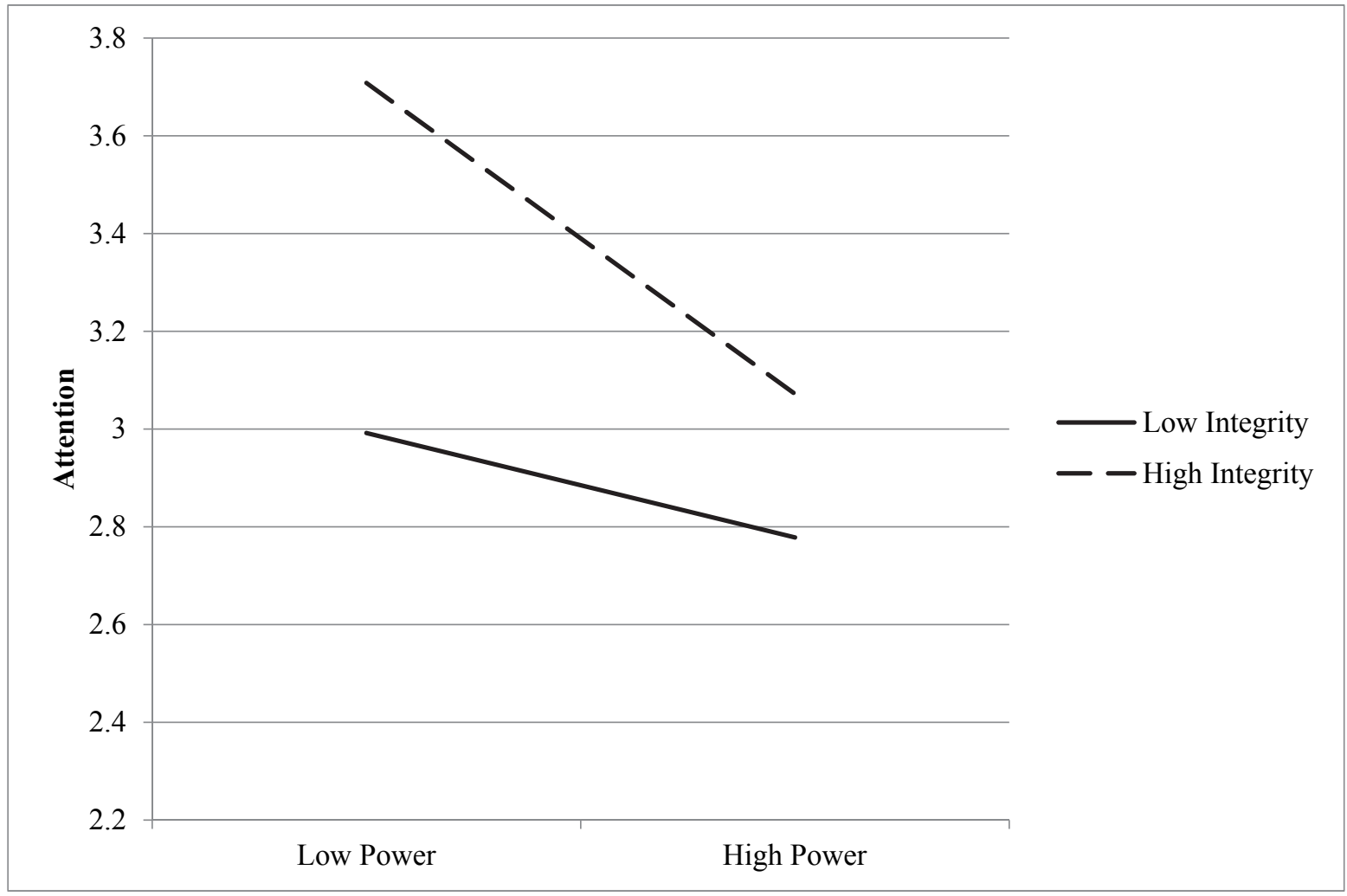

160 Journal of Organizational Psychology Vol. 19(2) 2019 